\title{
Effects of atmospheric oscillations on the field-aligned ion motions in the polar $F$-region
}

\author{
S. Oyama ${ }^{1}$, S. Nozawa ${ }^{2}$, S. C. Buchert ${ }^{2}$, M. Ishii ${ }^{1}$, S. Watari ${ }^{1}$, E. Sagawa ${ }^{1}$, W. Kofman ${ }^{3}$, J. Lilensten ${ }^{3}$, R. Fujii ${ }^{2}$ \\ ${ }^{1}$ Communications Research Laboratory, 4-2-1, Nukuikita-machi, Koganei, Tokyo, 184-8795, Japan \\ 2 Solar-Terrestrial Environment Laboratory, Nagoya University, Furo-cho, Chikusa-ku, Nagoya, 464-8601, Japan \\ ${ }^{3}$ Laboratoire de Planetologie de Grenoble Batiment D de Physique BP 53, 38041 Grenoble Cedex, France
}

Received: 2 February 2000 / Revised: 14 June 2000 / Accepted: 21 June 2000

\begin{abstract}
The field-aligned neutral oscillations in the $F$-region (altitudes between 165 and $275 \mathrm{~km}$ ) were compared using data obtained simultaneously with two independent instruments: the European Incoherent Scatter (EISCAT) UHF radar and a scanning FabryPerot interferometer (FPI). During the night of February 8, 1997, simultaneous observations with these instruments were conducted at Troms $\varnothing$, Norway. Theoretically, the field-aligned neutral wind velocity can be obtained from the field-aligned ion velocity and by diffusion and ambipolar diffusion velocities. We thus derived field-aligned neutral wind velocities from the plasma velocities in EISCAT radar data. They were compared with those observed with the FPI $(\lambda=630.0 \mathrm{~nm})$, which are assumed to be weighted height averages of the actual neutral wind. The weighting function is the normalized height dependent emission rate. We used two model weighting functions to derive the neutral wind from EISCAT data. One was that the neutral wind velocity observed with the FPI is velocity integrated over the entire emission layer and multiplied by the theoretical normalized emission rate. The other was that the neutral wind velocity observed with the FPI corresponds to the velocity only around an altitude where the emission rate has a peak. Differences between the two methods were identified, but not completely clarified. However, the neutral wind velocities from both instruments had peak-to-peak correspondences at oscillation periods of about 10-40 min, shorter than that for the momentum transfer from ions to neutrals, but longer than from neutrals to ions. The synchronizing motions in the neutral wind velocities suggest that the momentum transfer from neutrals to ions was thought to be dominant for the observed fieldaligned oscillations rather than the transfer from ions to neutrals. It is concluded that during the observation, the plasma oscillations observed with the EISCAT radar at
\end{abstract}

Correspondence to: S. Oyama

e-mail: oyama@crl.go.jp different altitudes in the $F$-region are thought to be due to the motion of neutrals.

Key words: Ionosphere (Ionosphere-atmosphere interactions) - Meteorology and atmospheric dynamics (thermospheric dynamics; waves and tides)

\section{Introduction}

Oscillations of plasma and neutral atmosphere in the ionosphere were studied theoretically by Hines (1960). Following his pioneer work, the field-aligned ionneutral interaction along with the effects of the ambipolar diffusion were formulated theoretically by Hooke (1968) and Testud and Francois (1971). Experimental evidence that agrees with previous theories has been reported, it was based on observations of neutral oscillations with all-sky imagers, photometers, and mass spectrometers on board satellites (e.g. Hedin and Mayr, 1987; Taylor and Edwards, 1991; Hines, 1993; Forbes et al., 1995) and on observations of plasma oscillations with incoherent scatter (IS) radars, $\mathrm{HF}$ and MF radars, ionosondes, and total electron contents when it was assumed that the plasma acts a passive tracer to display motions of the neutral atmosphere (e.g. Titheridge, 1968; Hajkowicz and Hunsucker, 1987; Rice et al., 1988; Hajkowicz, 1991; Williams et al., 1993; Manson et al., 1997). The observations also indicated that the propagation of traveling ionospheric disturbances is associated with atmospheric gravity waves (AGWs).

Modeling studies have suggested that the generation of AGWs at high latitudes is a direct response of the atmosphere to ionospheric disturbances at high latitudes (Richmond and Matsushita, 1975; Millward et al., $1993 \mathrm{a}, \mathrm{b})$. Ionospheric disturbances are associated with the electric field and electron precipitation in the auroral region, which enhance the thermal energy in the atmosphere through Joule/frictional heating and the 
heating due to the direct impact of incoming electrons with neutral particles. The thermal energy tends to expand the neutral atmosphere, producing pressure gradients that drive divergent flows vertically and/or horizontally. Generally, upward flows are generated during enhancement of the electric field and electron precipitation. When the enhancement relaxes, the heat source ceases to be effective, which stops the thermal expansion. The parcel then moves downward because the gravitational force overcomes the buoyancy one. Enhancement of the electric field and electron precipitation thus can result in vertical motion of the neutrals.

The dispersion relation of internal gravity waves (Hines, 1960) reveals that the period of neutral atmospheric waves must be longer than the Brunt-Väisälä period. The Brunt-Väisälä period is proportional to the ratio of the neutral temperature to the mean neutral mass. While the mean mass gradually decreases with height, the neutral temperature, as a first approximation, increases gradually with height in the $F$-region. The Brunt-Väisälä period thus normally increases with height. For example, in the auroral ionosphere, it is estimated to be about $11 \mathrm{~min}$ at $230 \mathrm{~km}$ and $13 \mathrm{~min}$ at $300 \mathrm{~km}$. The increase in the Brunt-Väisälä period with height indicates that the oscillation period of the neutrals also increases with height. Because the waves and oscillations have height-dependent features, incoherent scatter radars with good altitude resolution $(20$ $50 \mathrm{~km}$ in the $F$-region) are an appropriate tool for studying gravity waves.

Interactions between plasmas and neutrals can be described by coupled nonlinear partial differential equations such as the momentum equation, the energy equation, and the continuity equation, all of which must be solved together in order to estimate thermospheric motions, temperatures, and densities. Understanding the atmospheric motions in the thermosphere is difficult because the plasma affects the neutrals through frictional heating and momentum exchange. The plasma is, in turn, affected by the neutral motions through collisions. Hence, simultaneous observations of ion and neutral motions must be the basis for more sophisticated modeling efforts.

Simultaneous observations with IS radars and interferometers have been conducted in the auroral region (Nagy et al., 1974; Rees et al., 1984; Thuillier et al., 1990; Lilensten et al., 1992; Lathuillere et al., 1997). In the $F$-region, meridional neutral winds derived from European Incoherent Scatter (EISCAT) radar data showed relatively good agreement with the winds observed with the Michelson Interferometer for Coordinated Auroral Doppler Observations (MICADO interferometer) with a few discrepancies (Thuillier et al., 1990). These discrepancies were related to the assumption of negligible vertical neutral wind velocity in the derivation of the meridional wind velocity using EISCAT radar data. In addition, the meridional wind velocity derived from EISCAT radar data depends on the ion-neutral collision frequency, which has to be derived from a model. Lilensten et al. (1992) derived the meridional neutral wind velocity from EISCAT radar data considering the vertical neutral wind velocity, which was calculated from the MICADO interferometer temperature. They concluded that a vertical neutral wind velocity usually has a stronger effect on the derivation of the meridional wind velocity than ambipolar diffusion velocity.

Altitude profiles of the neutral wind velocity and the emission rate should be considered when estimating the effective height range of Fabry-Perot interferometer (FPI) measurements. A wind shear in the polar $F$-region has been observed using rockets that released a trimethyl aluminum chemical trail (Mikkelsen et al., 1981). The results suggest that the Lorentz force and Joule/frictional heating have a strong influence on the wind shear. Rees and Roble (1986) calculated the altitude at which the auroral red-line emission rate has a peak, and found that it is a function of the characteristic energy of the incident Maxwellian electron-energy spectra. The altitude decreases as the characteristic energy increases, from $240 \mathrm{~km}$ at $0.1 \mathrm{keV}$ to $180 \mathrm{~km}$ at $2.0 \mathrm{keV}$. The height-profile of the emission rate also depends on the neutral wind velocity due to local transport of neutral parcels ( Hays and Atreya, 1971; Sica et al., 1986). To estimate the effects of the variation in the altitude of the peak emission rate and of the wind shear as well as the neutral temperature gradient, McCormac et al. (1987) simulated the neutral wind velocity that would be observed with an FPI at a wavelength of $630.0 \mathrm{~nm}$. They found a discrepancy between the simulated neutral wind velocity and the exospheric velocity, which was caused by large vertical gradients of the neutral wind velocity.

This work describes the ionosphere-thermosphere interactions, focusing especially on a comparison of the field-aligned oscillations of neutrals in the $F$-region for periods from 14 to $55 \mathrm{~min}$ derived independently with the EISCAT UHF radar and with a scanning FPI at Troms $\varnothing$, Norway $\left(69.6^{\circ} \mathrm{N}, 19.2^{\circ} \mathrm{E}\right)$. Section 2 describes the instrumentation and data. Section 3 describes the method we used to estimate the neutral wind velocity derived from EISCAT radar data, the model we used to calculate the $630.0 \mathrm{~nm}$ emission rate, and the two methods we used to interpret the neutral wind velocity. Section 4 describes the observation results. The momentum transfer processes between ions and neutrals are discussed in Sect. 5.

\section{Instrumentation and data}

For the observation campaign from January 11 to February 13, 1997, two FPIs of the Communications Research Laboratory (CRL), Japan, were installed at the EISCAT radar site in Troms $\varnothing$ (Ishii et al., 1997). One was an all-sky-type FPI, and the other was a scanning-type FPI. In this work, the neutral wind velocity observed with the scanning FPI was used, because the scanning FPI had a full-view angle of $1.4^{\circ}$, which was almost the same as the full-power beam width of the EISCAT UHF antenna, about $1.2^{\circ}$. The scanning FPI was fixed to look along the geomagnetic field line 
during the night of February 8, as was the EISCAT UHF antenna. The same approximate cross section in the emission layer of the red-line was thus monitored by both instruments. When comparing data for these simultaneous observations, we do not need to make any assumptions about the horizontal or vertical neutral wind components because both instruments looked along the same field line.

The FPI measured auroral emissions at a wavelength of $557.7 \mathrm{~nm}$ (green-line) and $630.0 \mathrm{~nm}$ (red-line) simultaneously by dividing the incident auroral light into two paths with a dichroic mirror. We focused on the motions of the neutrals in the $F$-region, so we used only red-line emission data. The fringe images taken with the FPI were integrated over $60 \mathrm{sec}$. Because it took about $30 \mathrm{~s}$ to transfer each image from the instrument to a hard disk, the neutral wind velocity was obtained about every $90 \mathrm{~s}$. We calculated the running-average of the squared fringe radius over two hours to determine the artificial drifts in the neutral wind velocity due to etalon gap variations caused by unpreventable perturbations in room temperature and humidity. The drifts tend to have a comparatively long oscillation period of a few hours. We assumed that the effects of the etalon gap were negligible after subtracting running-averaged data from measured data.

The Doppler shift due to the neutral wind velocity causes variations of the fringe radius, and it does not change the center position of the fringe theoretically, if there is no horizontal gradient of the neutral motion and auroral intensity in the volume where the FPI observes. Thus, the fringe should have the same radius along the azimuth. We have assumed that the neutral wind velocity from the FPI can be derived from the Doppler shift averaged over the azimuth. However, some observed fringes showed a significant variation in the radius along the azimuth, which increased the statistical and systematic deviations in the neutral wind velocity. The radius variation might have been caused by a horizontal gradient of auroral intensity in the fieldof-view of the FPI. Considering the radius variations of the observed fringes, we assumed that an integration over about $7 \mathrm{~min}$ (corresponding to five fringes) was enough to derive the neutral wind velocity. The neutral wind velocities from the original fringe obtained about every $90 \mathrm{~s}$ were running-averaged over five data points. We were interested in oscillations at periods longer than 14 min.

The observation mode of the EISCAT UHF radar was identical to that of Common Program One version $\mathbf{J}$ except we modified the $E$-region heights of the common volume for tristatic measurements. The electron density, the ion and electron temperatures, and the field-aligned ion velocity were derived from an alternating code signal modulation, which covered 86 to $268 \mathrm{~km}$ with altitude resolution of about $3 \mathrm{~km}$, and from a long-pulse covering from 146 to $586 \mathrm{~km}$ with resolution of about $22 \mathrm{~km}$. IS analysis was made with an integration time of $90 \mathrm{~s}$, which was close to the sampling time of FPI data. The analysis results were then smoothed by calculating the running-average over five post-integrated periods.
In general, the emission occurs at altitudes between about 150 and $350 \mathrm{~km}$, so we used EISCAT radar data from this height range. There are, however, some caveats when using EISCAT radar data. The first gate of the long-pulse, at $143 \mathrm{~km}$, might give biased ionospheric data, because the altitude gradient of the electron density is frequently large over the height range covered by the first gate pulse. EISCAT radar data from the long-pulse code at altitudes higher than $297 \mathrm{~km} \mathrm{had}$ a few gaps due to the low SN ratio of the IS spectrum. Data from the alternating code signal at altitudes between 150 and $160 \mathrm{~km}$ had considerably large fitting errors. We thus used data at altitudes from 165 to $275 \mathrm{~km}$, that is, six gates.

The emission intensity of the red-line was measured using a photometer with a narrow view angle, $2^{\circ}$. The photometer was also fixed to look along the geomagnetic field line. The integration time was $0.1 \mathrm{~s}$. While there was a small discrepancy in the view angle, the photometer was assumed to have observed almost the same volume as the other instruments.

\section{Analysis}

The ion and neutral wind velocities along the magnetic field line, $V_{/ /}$and $U_{/ /}$, are related by (Winser et al., 1988 and references therein),

$U_{/ /}=V_{/ /}-\frac{g \sin I}{v_{i n}}-\frac{k}{m_{i} N v_{i n}} \frac{\partial}{\partial s}\left(N\left(T_{i}+T_{e}\right)\right)$,

where $g$ is the gravitational acceleration, $I$ is the magnetic dip angle, $v_{i n}$ is the ion-neutral collision frequency, $k$ is the Boltzmann constant, $m_{i}$ is the mean ion mass, $N$ is the ion density, and $T_{i}$ and $T_{e}$ are the ion and electron temperatures. $\partial\left(N\left(T_{i}+T_{e}\right)\right) / \partial s$ is the partial derivative of $N\left(T_{i}+T_{e}\right)$ with respect to the field-aligned direction.

The Mass Spectrometer Incoherent Scatter (MSIS) neutral atmosphere mode (Hedin, 1991) was used to estimate $v_{i n}$. The ion composition model to derive $N, T_{i}$, $T_{e}$, and $V_{/ /}$from the EISCAT radar spectrum was used to estimate $m_{i}$. EISCAT radar data were previously used to study the neutral wind velocity in the $F$-region (e.g. Thuillier et al., 1990; Lilensten et al., 1992; Lathuillere et al., 1997; Witasse et al., 1998). With an increase in geomagnetic activity, we expect enhanced energy input from the magnetosphere to the ionosphere. This enhancement, as described in Sect. 1, activates the vertical motion of neutral atmospheric parcels, which may alter the height profile of the ion composition. During geomagnetically disturbed periods, it is more difficult to derive the ion and electron temperatures and the electron density from IS spectrum than during geomagnetically quiet periods.

The results of Strickland et al. (1989) were used to calculate the red-line emission rate using data from the EISCAT radar and the MSIS model. The two major production processes of $\mathrm{O}\left({ }^{1} \mathrm{D}\right)$ are assumed to be electron impact excitation of atomic oxygen and dissociative recombination of molecular oxygen ions. 
The emission rate by electron impact excitation is proportional to the electron precipitation flux. The flux was estimated using a model equation in the energy range from $10 \mathrm{eV}$ to $10 \mathrm{keV}$ (Meier et al., 1989). To determine the characteristic energy and total energy flux, the model flux was fitted using the least square method to the flux derived from a method for calculating spectra using altitude profiles of electron density observed with the EISCAT radar. We used the CARD method (Brekke et al., 1989) to estimate incident energy spectra of precipitating electrons. The least square fitting was performed over an energy range from $2 \mathrm{keV}$ to $10 \mathrm{keV}$.

Meier et al. (1989) obtained relatively good agreement between the computed altitude profile of ion and electron densities and the one observed using a rocket (Sharp et al., 1979). The model densities were calculated taking into account ionization due to primary and secondary electrons. The electron transport model used was described by Strickland et al. (1976). The relatively good agreement suggests that ionization due to primary and secondary electrons is the major process for the electron density which directly relates to the emission rate. The emission rate model thus included the effects of primary and secondary electrons.

The altitude resolution of FPI data is inevitably limited by the shape of the emission profile. The field- aligned component of the neutral wind velocity derived from the FPI, $U_{/ / \mathrm{FPI}}$, depends on the neutral motions in the entire emission height range monitored with the FPI, though the neutral motion at altitudes where the emission rate has a peak will affect $U_{/ / \text {FPI }}$ more significantly than that at other altitude. We will use two methods, I and II, to interpret $U_{/ / \text {FPI }}$ :

I. $U_{\|}^{(I)}$ is the height-averaged velocity over the emission layer $\left(h_{1} \leq h \leq h_{2}\right)$ to the normalized emission rate at the peak value:

$U_{/ /}^{(I)}=\int_{h_{1}}^{h_{2}} \sigma(h) U_{/ / \operatorname{EISCAT}}(h) \mathrm{d} h / \int_{h_{1}}^{h_{2}} \sigma(h) \mathrm{d} h$,

where $\sigma(h)$ is the emission rate of the auroral red-line as a function of height, $h_{1}$ and $h_{2}$ stand for the altitudes of 165 and $275 \mathrm{~km}$, respectively, and $U_{/ / \text {EISCAT }}$ is the fieldaligned neutral wind velocity derived from EISCAT radar data and from the MSIS model according to Eq. (2).

II. $U_{\| /}^{(I I)}$ corresponds to the neutral wind velocity only around an altitude where the emission rate has a peak:

$U_{/ /}^{(I I)}=\left.U_{/ / \text {EISCAT }}\right|_{h=\text { max. emission height }}$.

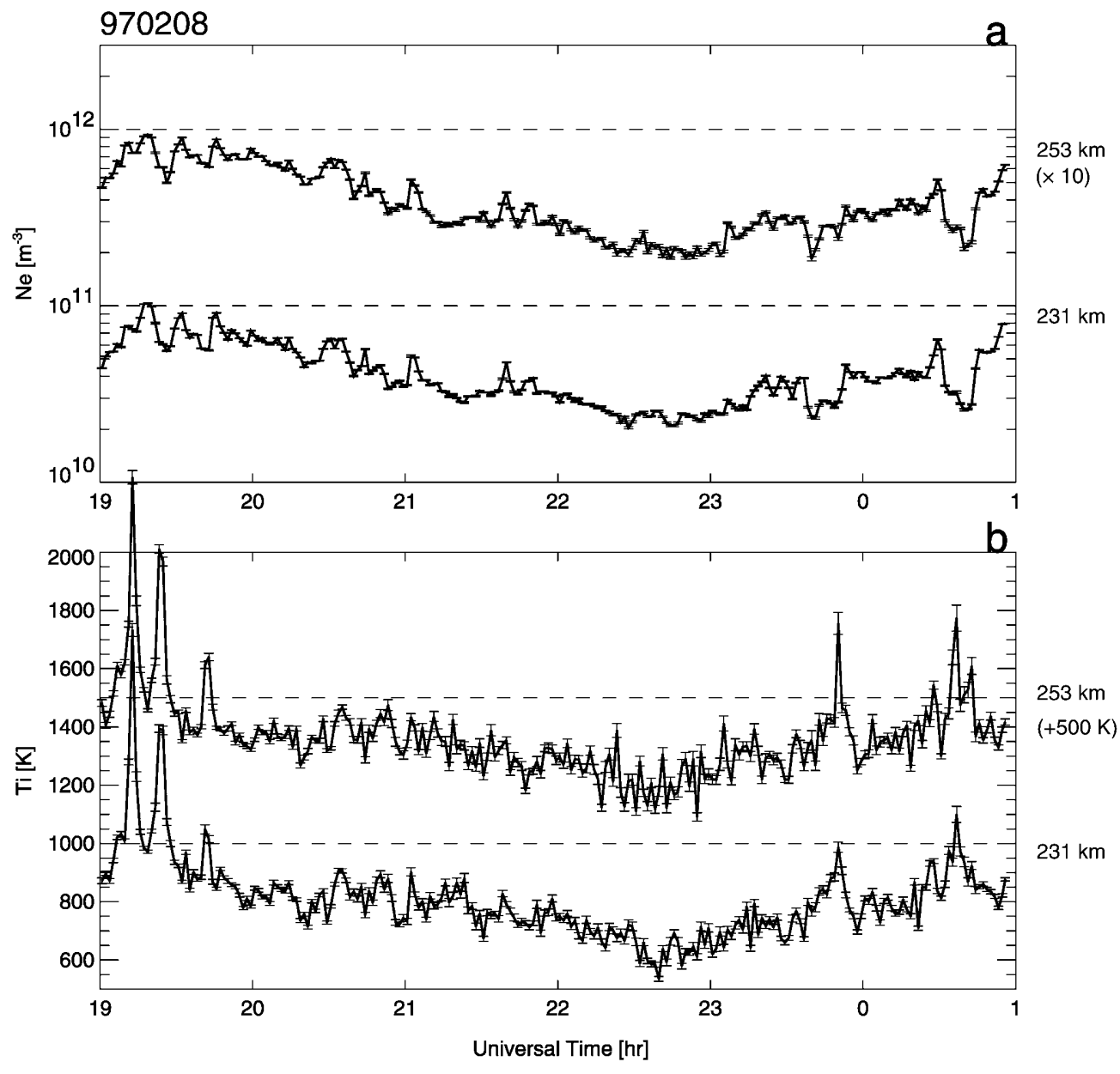

Fig. 1. a EISCAT electron density and $\mathbf{b}$ ion temperature as a function of time at altitudes of 231 and $253 \mathrm{~km}$. The electron density at $253 \mathrm{~km}$ is multiplied by 10 , and the ion temperature at $253 \mathrm{~km}$ is shifted by $500 \mathrm{~K}$ to avoid overlapping 


\section{Observation results}

Figure 1 shows temporal variations of the electron densities (Fig. 1a) and the ion temperatures (Fig. 1b) observed with the EISCAT radar at two $F$-region heights (231 and $253 \mathrm{~km})$ during the simultaneous observation period on February 8. Between 1900 and 2000 UT and 2330 and 0100 UT, the electron densities at both heights varied with fluctuation amplitudes of greater than $6 \times 10^{10} \mathrm{~m}^{-3}$ presumably due to electron precipitation. The ion temperatures at both heights also fluctuated due to Joule and frictional heating. The graphs show that the large enhancements of the ion temperature (at 1912, 1922, 1940, 2349, and 0036 UT) coincided with reductions in the electron density. After the enhancements, the electron density increased immediately. This asymmetry between the ion temperature and the electron density can be associated with heating and electron precipitation in the vicinity of an auroral arc (Marklund, 1984). It appears that energies are deposited into the ionosphere due to Joule/frictional as well as particle heating during the geomagnetically active periods. Because the derivation of the neutral wind velocity from EISCAT radar data is less accurate during these active periods, we must be careful when using EISCAT radar data when strong fluctuations in density and temperatures are observed. The electron densities and the ion temperatures from 2000 to 2330 UT showed smaller fluctuations than the densities and temperatures during the disturbed periods. While the electron densities showed burst enhancements at around 2030, 2102, and 2138 UT, these small fluctuations suggest that we can derive the neutral wind velocities during the quiet period more reliably.

Figure 2a shows $U_{/ / \text {FPI }}$ including some data gaps. A running-average over five data points after interpolating over the gaps with a linear function was performed, so that the gaps are not visible in the curve. The periods with the gaps were shaded darker gray. The periods when the fringe radius variations, noted in Sect. 2, were remarkable were shaded lighter gray. We compared the neutral wind velocity in three periods: (A) 1912-2020 UT, (B) 2106-2218 UT, and (C) 2310-0100 UT. A positive wind is shown moving upward along the field line.

Figure $2 \mathrm{~b}$ shows $U_{/ / \text {EISCAT }}$ at altitudes from 165 to $275 \mathrm{~km}$. EISCAT radar data from 165 to $275 \mathrm{~km}$ had no data gaps, and had relatively small fitting errors. If the ion composition model for the IS spectrum analysis has a relatively large ambiguity for the disturbed periods,
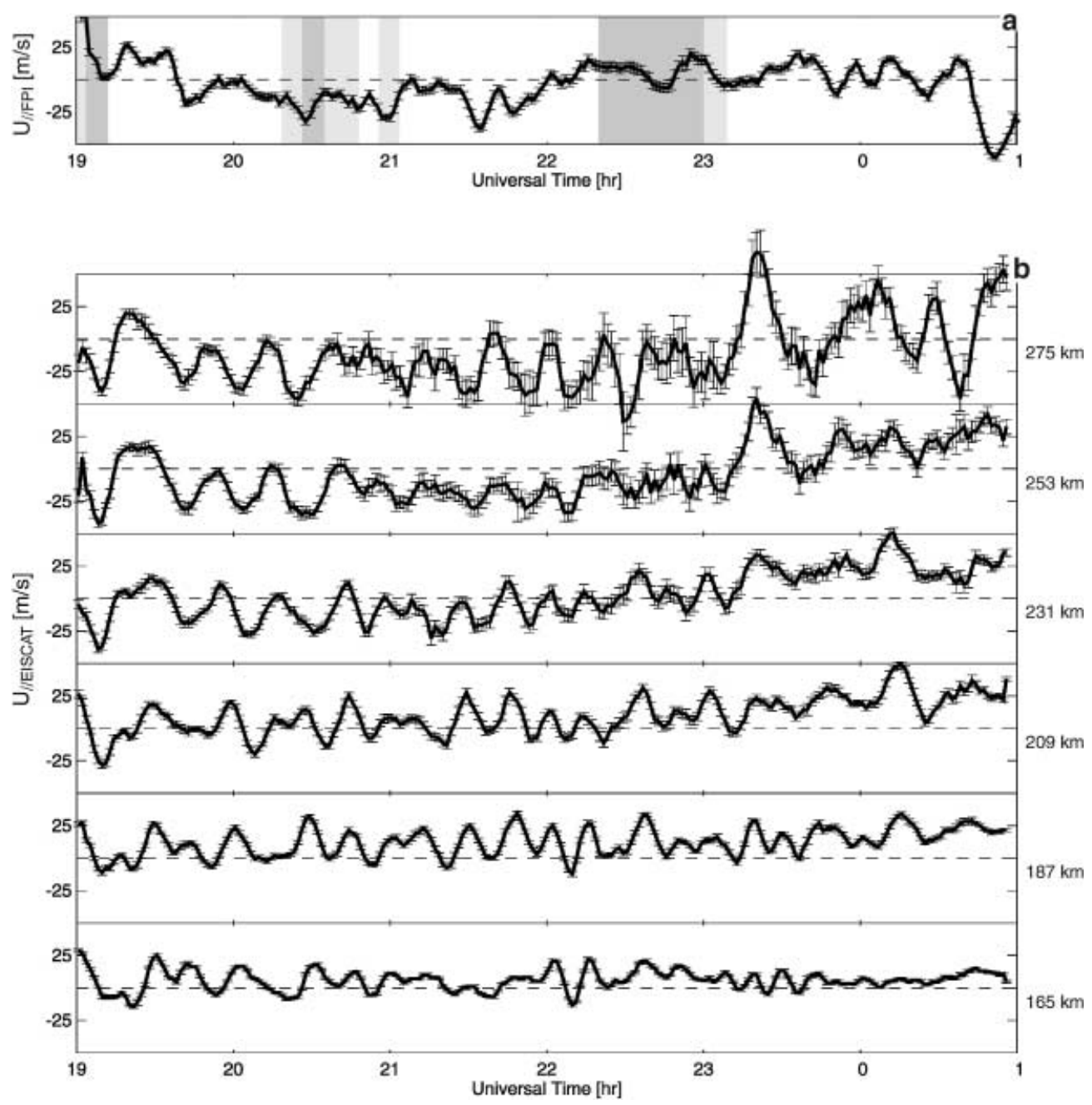

Fig. 2. a Field-aligned neutral wind velocity observed with the scanning FPI, and $\mathbf{b}$ derived from EISCAT UHF radar data with height range from 165 to $275 \mathrm{~km}$. Winds are positive upward along the field line. Shaded parts in upper panel are explained in the text 


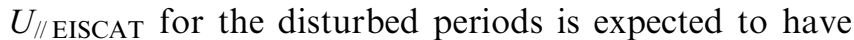
larger errors than for the quiet periods because the large fitting error of EISCAT radar data introduces a higher uncertainty to the diffusion velocity. However, the size of the error bars in Fig. 2b did not change greatly during the observation period. It suggests that the uncertainty of the ion composition model did not strongly affect $U_{/ / \text {EISCAT }}$ in this height range. Using Fourier analysis, the oscillation periods of the neutral wind velocities at these altitudes ranged from 14 to $32 \mathrm{~min}$, which were longer than the Brunt-Väisälä period in this height range. Fourier analysis showed that the mean amplitudes of the oscillation of $U_{/ / \text {EISCAT }}$ increased with height. Cross-correlation analysis between $U_{/ / \text {EISCAT }}$ at altitude of $275 \mathrm{~km}$ and other altitudes showed height dependence of the phase (Table 1). The decrease in the time lag with height is consistent with the simulation by Kirchengast (1997). A forward phase propagation with decreasing altitude was not seen. The phase propagation will be seen if $U_{/ / \text {EISCAT }}$ are derived at altitudes lower than $160 \mathrm{~km}$, because, in general, it becomes easy to see

Table 1. Cross-correlation coefficient and time lag between $U_{/ / \text {EISCAT }}$ at altitude of $275 \mathrm{~km}$ and at another heights for period A

\begin{tabular}{llllll}
\hline Altitude $(\mathrm{km})$ & 165 & 187 & 209 & 231 & 253 \\
$\begin{array}{c}\text { Cross-correlation } \\
\text { coefficient }\end{array}$ & 0.56 & 0.65 & 0.70 & 0.85 & 0.95 \\
\begin{tabular}{c} 
Time lag (min) \\
\hline
\end{tabular} & 12.0 & 10.5 & 7.5 & 4.5 & 1.5 \\
\hline
\end{tabular}

with decreasing altitude. Using Fourier and crosscorrelation analysis, the wave-like structures observed with the EISCAT radar are probably associated with AGWs.

Figure $3 \mathrm{a}$ shows the altitude profile of the red-line emission rate calculated using EISCAT radar data. The emission rate was normalized by the maximum value at 1945 UT at altitude of $231 \mathrm{~km}$. The thick line is the altitude where the emission rate has a peak. This altitude was used to derive the neutral wind velocity for method II. The altitude of the peak emission rate was $231 \mathrm{~km}$ before 2100 UT. After 2100 UT, the altitude fluctuates between two gates, however, it is difficult to discuss the altitudinal variation of the peak emission rate from this fluctuation. During the observation, the altitude is expected to have been rather constant at around $231 \mathrm{~km}$. The thickness of the emission layer was defined as the width where the emission rate is larger than 1/e of the peak value. Solid circles show the upper and lower boundaries of the emission layer. The boundaries sometimes moved below and/or above the height range, from 165 to $275 \mathrm{~km}$, covered by EISCAT radar data in use. In that case, the solid circles were dotted out of the height range. When the upper and lower boundaries of the emission layer were within the height range, we could estimate the FPI neutral wind velocity from EISCAT radar data for method I. However, when the boundaries were out of the height range, the estimation may have had larger ambiguities on the amplitude and the phase of the neutral wind velocity from EISCAT a
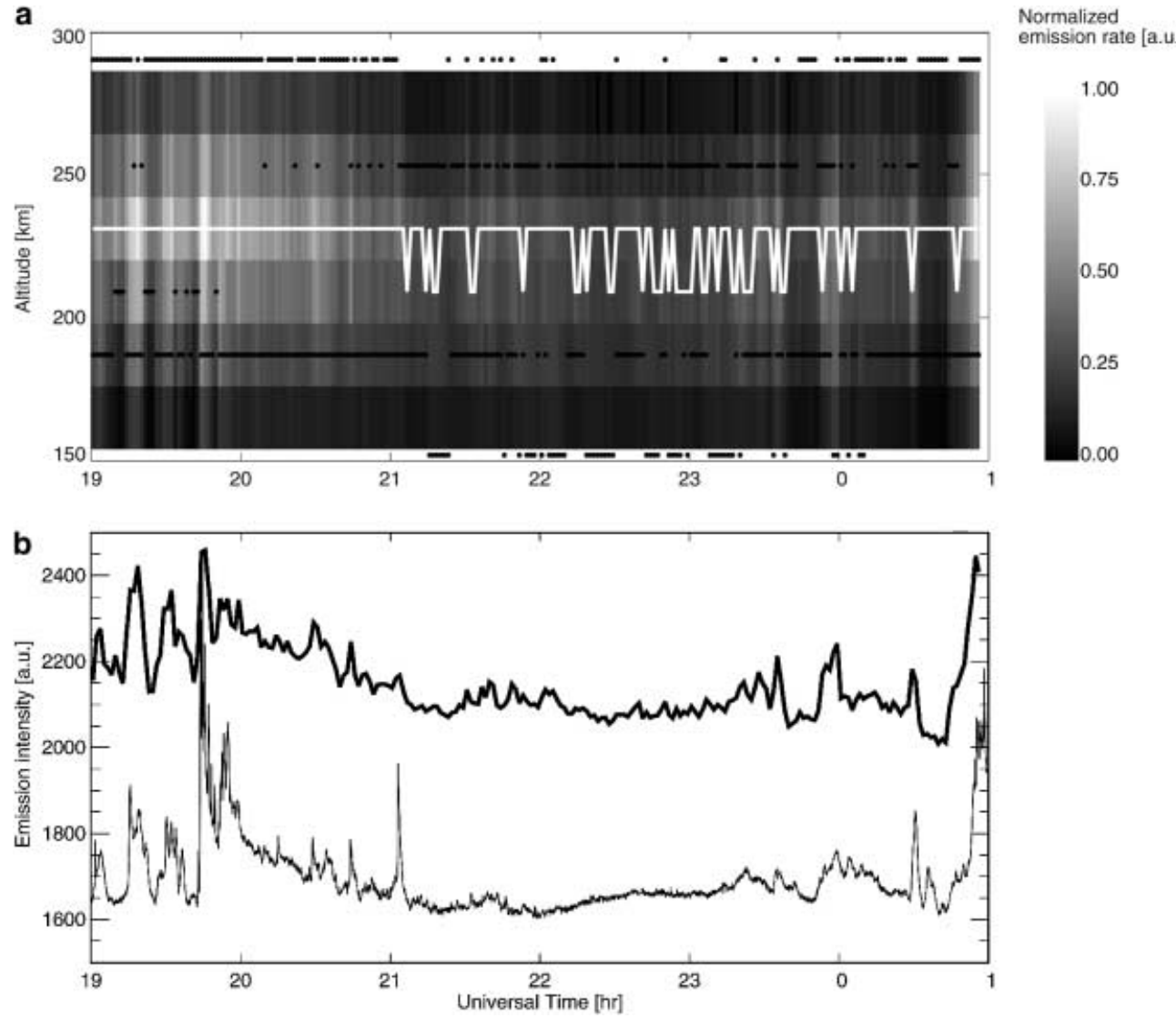

Fig. 3. a Altitude profile of redline emission rate calculated using EISCAT radar data. Thick line shows altitude where the emission rate has a peak. The solid circles show the upper and lower boundaries of the emission layer, and those out of the height range (165 to $275 \mathrm{~km})$ show the upper or lower boundaries that are not within the height range. b The $630.0 \mathrm{~nm}$ count profile observed with photometer along the field line (thin line), and integrated emission rate over height range from 165 to $275 \mathrm{~km}$ (thick line) 
radar data. The effects of the emission layer thickness on the amplitude and phase relation will be discussed in Sect. 5.

Figure $3 \mathrm{~b}$ shows the photometer count and the emission rate integrated over the height range from 165 to $275 \mathrm{~km}$ on the basis of the normalized rate in Fig. $3 \mathrm{a}$. The photometer data are plotted every $5 \mathrm{~s}$ by the thin line. The integrated emission rate is plotted by the thick line, which is shifted and multiplied by a factor to avoid overlapping. Cross-correlation coefficient between the photometer and the derived total emission is 0.81 with the maximum showing no time lag. The relatively high value suggests that our emission model in combination with observed ionospheric data reflects the temporal behavior of the real emission quite accurately.

Figure 4a shows $U_{/ / \text {FPI }}$ and Fig. 4(b) shows $U_{/ /}^{(I)}$ (thick line) and $U_{\|}^{(I I)}$ (thin line). The shading is the same as in Fig. 2a. While there are discrepancies in the amplitudes between $U_{\|}^{(I)}$ and $U_{\|}^{(I I)}$, both neutral winds have similar wave-like structures.

To investigate the amplitude and the phase in more detail, we performed Fourier analysis on $U_{\|}^{(I)}, U_{\|}^{(I I)}$, and $U_{/ / \text {FPI }}$ for periods A, B, and C. The thick lines with solid circles in Fig. 5 are the spectra of $U_{/ / \text {FPI }}$. The thick lines with open circles are the spectra of $U_{\|}^{(I)}$, and the dashed lines with open circles are those of $U_{\|}^{(I I)}$. The shortest
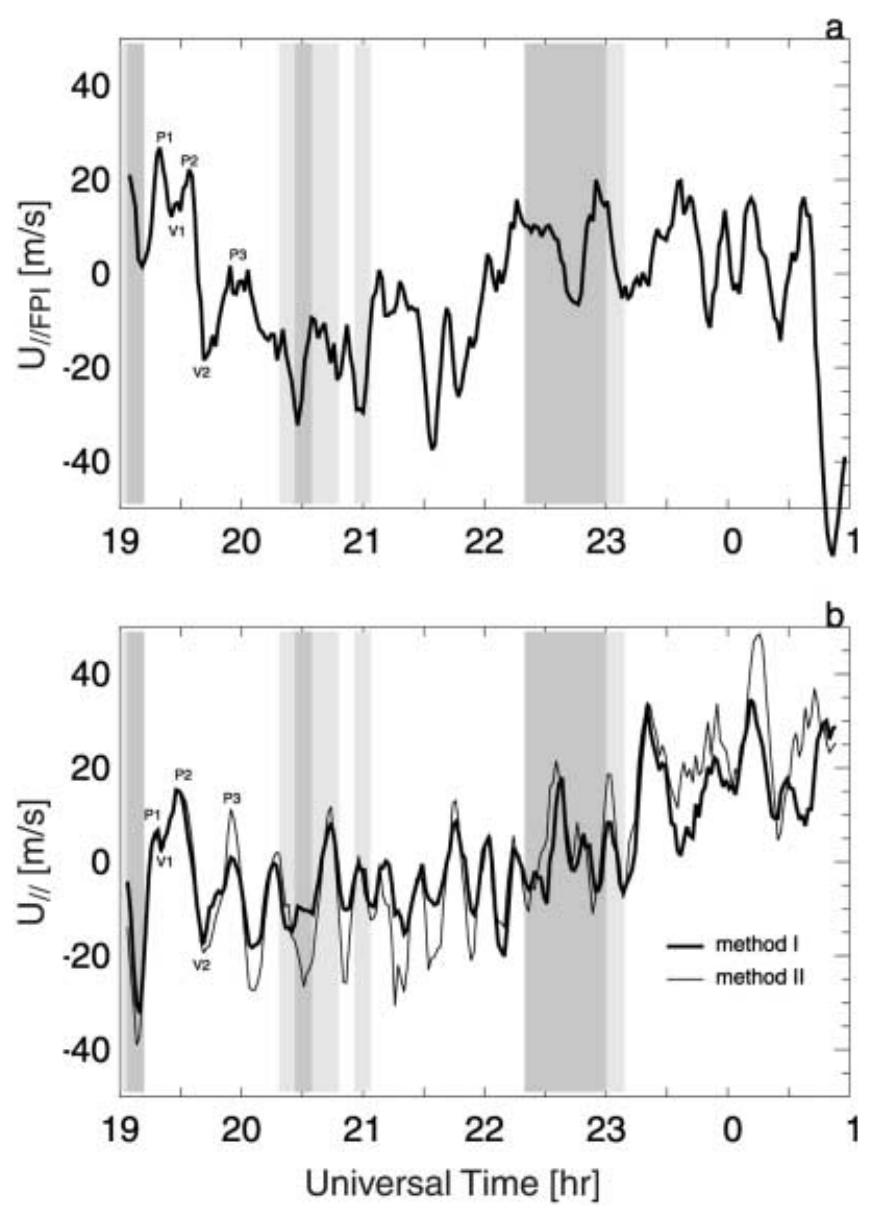

Fig. 4. a Field-aligned neutral wind velocity derived from the scanning FPI, and $\mathbf{b}$ from EISCAT radar data for methods I and II period in which we are interested is $14 \mathrm{~min}$, as mentioned in Sect. 2, and the longest one corresponds to the half length of each period: $34 \mathrm{~min}$ for period A, $36 \mathrm{~min}$ for period $\mathrm{B}$, and $55 \mathrm{~min}$ for period $\mathrm{C}$. The shortest and longest periods are marked with the vertical dashed lines. This spectrum analysis including the phase relation produced the following results.

1. Oscillation period and amplitude. Table 2 shows the amplitudes which correspond to an integrated one over the selected components: 14-34 min for period A, 14-36 min for period $\mathrm{B}$, and $14-55 \mathrm{~min}$ for period $\mathrm{C}$. For periods $\mathrm{A}$ and $\mathrm{B}$, the amplitudes of $U_{\| /}^{(I I)}$ were closer to those of $U_{/ / \text {FPI }}$ than those of $U_{/ /}^{(I)}$. For period C, the amplitudes of $U_{\|}^{(I)}$ and $U_{\|}^{(I I)}$ were smaller than that of $U_{/ / \text {FPI }}$.

Figure 5 shows that, for period A, the spectrum of $U_{\| I}^{(I)}$ was similar to that of $U_{\| I I}^{(I I)}$, though there was a difference in the amplitude at about $17 \mathrm{~min}$. For period $\mathrm{B}$, while there was also a difference in the amplitude at about $35 \mathrm{~min}$, the spectrum of $U_{\|}^{(I)}$ showed good agreement with that of $U_{\|}^{(I I)}$. These good agreements suggest that the neutral wind velocity at around the altitude of the peak emission rate represents the velocity for method $\mathrm{I}$, approximately. For period $\mathrm{C}$, the amplitudes for methods I and II showed relatively large differences at about 21 and $35 \mathrm{~min}$, though the amplitudes at periods of about 15 and 52 min showed good agreements.

For period A, the spectra showed discrepancies in amplitude between $U_{/ / \text {FPI }}$ and $U_{/ /}^{(I)}$ and between $U_{/ / \text {FPI }}$ and $U_{\|}^{(I I)}$. At about $17 \mathrm{~min}$, the amplitude of $U_{\|}^{(I I)}$ was larger than that of $U_{/ / \text {FPI }}$ by a factor of three. At about 22 and $33 \mathrm{~min}$, the amplitudes of $U_{\|}^{(I)}$ and $U_{\|}^{(I I)}$ were smaller than that of $U_{/ / \text {FPI }}$. For period B, the spectra of $U_{\|}^{(I)}$ and $U_{\|}^{(I I)}$ agreed fairly well with the spectrum of $U_{/ / \text {FPI }}$, except for the amplitudes at about 23 and $35 \mathrm{~min}$. The three spectra had peak amplitudes at about $14 \mathrm{~min}$. For period C, the spectra of $U_{/ / \text {FPI }}$ and $U_{\| /}^{(I)}$ had similar trend in amplitude from about 21 to about $35 \mathrm{~min}$, though there were large discrepancies in the magnitude (by a factor of about three). The spectrum of $U_{/ / \text {FPI }}$ and $U_{\|}^{(I I)}$ had a peak at about $21 \mathrm{~min}$. A reason for the discrepancy in amplitude will be discussed in Sect. 5 as well as for the phase relation.

2. Cross-correlation and phase relation. Table 3 shows cross-correlation coefficient and time lag. For period A, the cross-correlation coefficients were relatively high, and the time lags were small. The significance was quite high so that oscillations of $U_{\|}^{(I)}$ and $U_{\|}^{(I I)}$ were thought to synchronize with those of $U_{/ / \text {FPI }}$. For period B, while the significances were also quite high, the cross-correlation coefficients and the time lags probably did not suggest synchronized oscillations between $U_{/ /}^{(I)}$ and $U_{/ / \text {FPI }}$ and

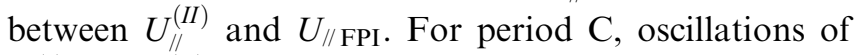
$U_{\| /}^{(I)}$ and $U_{\|}^{(I I)}$ were not thought to correlate with those of $U_{/ / \text {FPI }}$ according to low cross-correlation coefficients, long time lags, and low significances. 

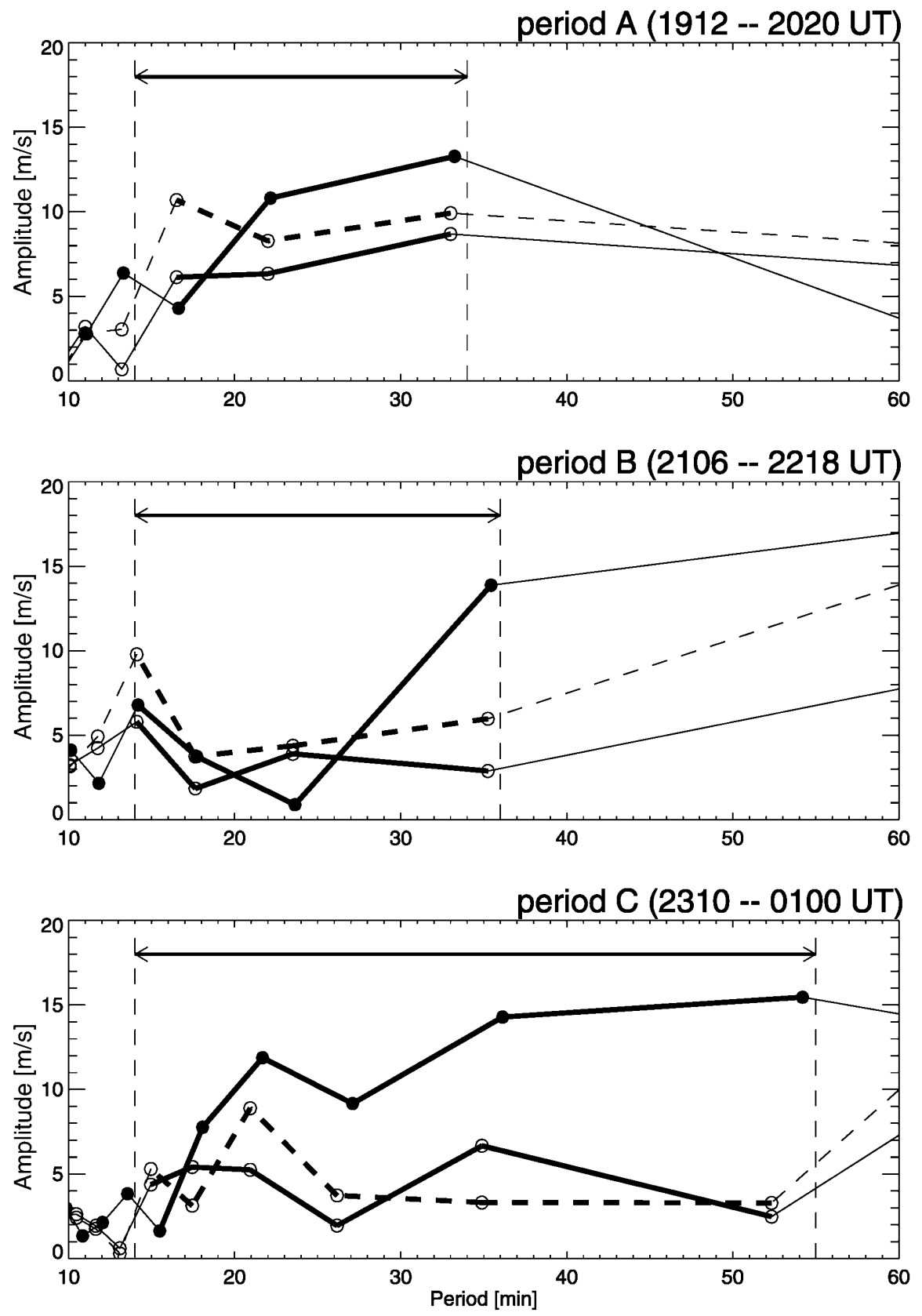

Fig. 5. Results of spectrum analysis of the field-aligned neutral wind velocities shown in Fig. 4. Thick lines with solid circle are the spectra of the neutral wind velocity observed with the FPI. Thick lines with open circles are the spectra of the neutral wind velocity for method I, and dashed lines with open circles are for method II. The vertical dashed lines show the shorter and longer periods used to compare the spectra: 14 and 34 min for period A, 14 and 36 min for period $\mathrm{B}$, and 14 and $55 \mathrm{~min}$ for period $\mathrm{C}$
Table 2. Integrated ampltitude of $U_{/ / \mathrm{FPI}}$ and $U_{/ /}^{(I)}$, and $U_{/ /}^{(I I)}$ over selected period components

\begin{tabular}{llll}
\hline & $\mathrm{A}(\mathrm{m} / \mathrm{s})$ & $\mathrm{B}(\mathrm{m} / \mathrm{s})$ & $\mathrm{C}(\mathrm{m} / \mathrm{s})$ \\
\hline$U_{/ / \text {FPI }}$ & 28 & 25 & 60 \\
$U_{/ /}^{(I)}$ & 21 & 14 & 26 \\
$U_{/ /}^{(I I)}$ & 28 & 23 & 27 \\
\hline
\end{tabular}

\section{Discussion and conclusion}

We made a comparison between the field-aligned ion and neutral motions based on simultaneous EISCAT and FPI observations. The spectra of $U_{/ I}^{(I)}, U_{/ I}^{(I I)}$, and $U_{/ / \text {FPI }}$ expressed oscillation periods from 14 to $55 \mathrm{~min}$, as shown in Fig. 5. One dominant oscillation period is
Table 3. Cross-correlation coefficient and time lag between $U_{/ /}^{(I)}$ and $U_{/ / \text {FPI }}$ and between $U_{/ /}^{(I I)}$ and $U_{/ / \text {FPI }}$ Significance of the crosscorrelation coefficient is also tablated

\begin{tabular}{|c|c|c|c|c|c|c|}
\hline & \multicolumn{2}{|l|}{ A } & \multicolumn{2}{|l|}{ B } & \multicolumn{2}{|l|}{$\mathrm{C}$} \\
\hline & I & II & I & II & I & II \\
\hline $\begin{array}{l}\text { Cross-correlation } \\
\text { coefficient }\end{array}$ & 0.792 & 0.718 & 0.525 & 0.633 & 0.150 & 0.153 \\
\hline Time lag (min) & 3.0 & 1.5 & 13.5 & 15.0 & 15.0 & 3.0 \\
\hline Significance & $>0.99$ & $>0.99$ & $>0.99$ & $>0.99$ & $>0.70$ & $>0.70$ \\
\hline
\end{tabular}

about 14 min, which is close to the Brunt-Väisälä period in the $F$-region. The observed wave-like structures in other dominant oscillation periods appear to be internal gravity waves because the periods are above the BruntVäisälä period in the $F$-region. 
There are two processes for momentum transfer between ion and neutral particles. One is momentum transfer from ions to neutrals, which takes more than one hour in the $F$-region. The other is momentum transfer from neutrals to ions, which takes only a few seconds in the $F$-region. The former process makes the neutrals oscillate with the same periods as the ions if the ions oscillate at periods of more than one hour. $U_{/ / \text {FPI }}$ from 1900 UT, shown in Fig. 4a, gradually shifted from upward to downward along the field line, which had a minimum value of $-37 \mathrm{~m} / \mathrm{s}$ at $2134 \mathrm{UT}$. The amplitude of $U_{/ / \text {FPI }}$ then decreased up to the end of period B. For period $\mathrm{C}$, significant oscillations at a long period cannot be seen. While there were discrepancies in the amplitude, oscillations of $U_{\|}^{(I)}$ and $U_{\|}^{(I)}$ were similar to those of $U_{/ / \text {FPI }}$. This indicates that neutral motions at periods of longer than one hour are estimated using EISCAT radar data. This agreement is consistent with the results of comparing meridional wind velocities observed with the EISCAT radar and with the MICADO interferometer (Thuillier et al., 1990). This similarity, however, does not mean that the former momentum transfer process is a major in the motions at periods of longer than one hour because the latter momentum transfer process can also make ions oscillate at periods of longer than one hour if neutrals oscillate at longer periods.

In the case of the latter momentum transfer process, ions are capable of oscillating at almost the same amplitudes as the neutrals, propagating in phase with the neutrals. Thus, the latter process should produce a high cross-correlation coefficient with no time lag between $U_{/ /}^{(I)}$ and $U_{/ / \text {FPI }}$ and between $U_{/ /}^{(I I)}$ and $U_{/ / \text {FPI. }}$.

For period A, the upper boundaries of the emission layer in Fig. 3a moved above the altitude of $275 \mathrm{~km}$ most of the time. The lack of neutral wind velocity at altitudes higher than $275 \mathrm{~km}$ results in underestimation of amplitude of $U_{\|}^{(I)}$ because, in general, the neutral wind amplitude increases with height in the $F$-region (Witasse et al., 1998). This is because the integrated amplitudes of $U_{\|}^{(I)}$ were smaller than the amplitude of $U_{/ / \text {FPI }}$, as shown in Table 2 . The neutral wind velocity at lower altitude tend to contribute to the phase of $U_{/ / \text {FPI }}$ more significantly than those at higher altitude because of a forward phase propagation with decreasing altitude. For period A, $U_{\| /}^{(I)}$ was thought to reflect all the neutral wind motions that affected the phase relation of $U_{/ / \text {FPI }}$, because the lower boundaries of the emission layer were always higher than the bottom of the height range covered by EISCAT radar data. This is because, for period $\mathrm{A}$, the cross-correlation coefficient was relatively high, and the time lag was relatively small, as shown in Table 3.

For periods $\mathrm{B}$ and $\mathrm{C}$, the emission layers seem to have been thinner than those for period $\mathrm{A}$, as shown in Fig. 3a. The thin layer may have expected that the amplitude and the phase of $U_{\| /}^{(I)}$ can be close to those of $U_{/ / \text {FPI }}$ because the altitudinal ambiguity in the FPI data becomes small. The frequent expansion and down/up shifting of the emission layer, however, seem to have affected the amplitude and phase more seriously. The upper boundaries of the emission layer were sometimes higher than the altitude of $275 \mathrm{~km}$, resulting in underestimation of the amplitude of $U_{\|}^{(I)}$. This is consistent with the discrepancies in the integrated amplitude in Table 2. The lower boundaries of the emission layer frequently shifted below the altitude of $165 \mathrm{~km}$, resulting in an incorrect phase relation of $U_{\| l}^{(I)}$. This is because the phase relations for periods $\mathrm{B}$ and $\mathrm{C}$ had relatively low cross-correlation coefficients and large time lags, as shown in Table 3.

The peak-to-peak correspondence between $U_{\|}^{(I)}$ and $U_{/ / \text {FPI }}$ and between $U_{/ /}^{(I I)}$ and $U_{/ / \text {FPI }}$ can be seen in Fig. 4 for periods A, B, and C. For instance, for period A, the oscillations of $U_{/ / \text {FPI }}$ had three maxima (P1, P2, and P3) and two minima (V1 and V2). These oscillations are thought to consist of two wave structures, one with a period of about $33 \mathrm{~min}$, and the other with a period of about 22 min (see top panel of Fig. 5). Similar wave structures were also visible in $U_{\|}^{(I)}$ and $U_{\| /}^{(I I)}$ for period A. These oscillation periods are shorter than that for the momentum transfer from ions to neutrals. The momentum transfer from neutrals to ions is thus dominant for the observed field-aligned oscillations rather than the momentum transfer from ions to neutrals.

The summary of the EISCAT-FPI comparison is that the amplitude and the phase of $U_{/ / \text {FPI }}$ have been estimated using EISCAT radar data when the height range covered by EISCAT radar data in use has overlapped the emission layer. It is concluded that the plasma oscillations observed with the EISCAT radar at different altitudes in the $F$-region are thought to be due to the motion of neutrals.

Acknowledgements. The simultaneous EISCAT and FPI observations were conducted under international collaboration among Norway, France, Germany, and Japan between January 11 and February 13, 1997. We are indebted to the director and staff of EISCAT for operating the facility and supplying data. We are pleased to acknowledge the considerable assistance of Dr. Hirotaka Mori. We also would like to express our appreciation to Dr. Iwao Iwamoto. EISCAT is an international Association supported by Finland (SA), France (CNRS), The Federal Republic of Germany (MPG), Japan (NIPR), Norway (NFR), Sweden (NFR), and the United Kingdom (PPARC). This study was supported in part by the Grants-in-aid for International Scientific Research (09044074) and by Grants-in-aid for Scientific Research A (08304030) and B (08454135) from the Ministry of Education, Science, Sports and Culture, Japan. The CRL FPIs were developed for the US-Japan International Research Project to observe the middle atmosphere.

Topical Editor M. Lester thanks B. Watkins and another referee for their help in evaluating this paper.

\section{References}

Brekke, A., C. Hall, and T. L. Hansen, Auroral ionospheric conductances during disturbed conditions, Ann. Geophysicae, 7, 269-280, 1989.

Forbes, J. M., F. A. Marcos, and F. Kamalabadi, Wave structures in lower thermosphere density from satellite electronics triaxial accelerometer measurements, J. Geophys. Res., 100, 14 69314701, 1995.

Hajkowicz, L. A., Auroral electrojet effect on the global occurrence pattern of large-scale travelling ionospheric disturbances, Planet. Space Sci., 39, 1189-1196, 1991. 
Hajkowicz, L. A., and R. D. Hunsucker, A simultaneous observation of large-scale periodic TIDs in both hemispheres following an onset of auroral disturbances, Planet. Space Sci., 35, 785791, 1987.

Hays, P. B., and S. K. Atreya, The influence of thermospheric winds on the auroral red-line profile of atomic oxygen, Planet. Space Sci., 19, 1225-1228, 1971.

Hedin, A. E., Extension of the MSIS thermosphere model into the middle and lower atmosphere, J. Geophys. Res., 96, 1159-1172, 1991.

Hedin, A. E., and H. G. Mayr, Characteristics of wavelike fluctuations in dynamics explorer neutral composition data, J. Geophys. Res., 92, 11 159-11 172, 1987.

Hines, C. O., Internal atmospheric gravity waves at ionospheric heights, Can. J. Phys., 38, 1441-1481, 1960.

Hines, C. O., J. Atmos. Terr. Phys., 55, 197-199, 1993.

Hooke, W. H., Ionospheric irregularities produced by internal atmospheric gravity waves, J. Atmos. Terr. Phys., 30, 795-823, 1968.

Ishii, M., S. Okano, E. Sagawa, S. Watari, H. Mori, I. Iwamoto, and Y. Murayama, Development of Fabry-Perot interferometers for airglow observations, Proc. NIPR Symp. Upper Atmos. Phys., 10, 97-108, 1997.

Kirchengast, G., Characteristics of high-latitude TIDs from different causative mechanisms deduced by theoretical modeling, J. Geophys. Res., 102, 4597-4612, 1997.

Lathuillere, C., J. Lilensten, W. Gault, and G. Thuillier, Meridional wind in the auroral thermosphere: results from EISCAT and WINDII- $\left(O^{1} \mathrm{D}\right)$ coordinated measurements, J. Geophys. Res., 102, 4487-4492, 1997.

Lilensten, J., G. Thuillier, C. Lathuillere, W. Kofman, V. Fauliot, and M. Herse, EISCAT-MICADO coordinated measurements of meridional wind, Ann. Geophysicae, 10, 603-618, 1992.

Manson, A. H., C. E. Meek, and Q. Zhan, Gravity wave spectra and direction statistics for the mesosphere as observed by MF radars in the Canadian Prairies $\left(49^{\circ} \mathrm{N}-52^{\circ} \mathrm{N}\right)$ and Troms $\varnothing$ $\left(69^{\circ} \mathrm{N}\right)$, J. Atmos. Terr. Phys., 59, 993-1009, 1997.

Marklund, G., Auroral arc classification scheme based on the observed arc-associated electric field pattern, Planet. Space Sci., 32, 193-211, 1984.

McCormac, F. G., T. L. Killeen, B. Nardi, and R. W. Smith, How close are ground-based Fabry-Perot thermospheric wind and temperature measurements to exospheric values? A simulation study, Planet. Space Sci., 35, 1255-1265, 1987.

Meier, R. R., D. J. Strickland, J. H. Hecht, and A. B Christensen, Deducing composition and incident electron spectra from ground-based auroral optical measurements: a study of auroral red line processes, J. Geophys. Res., 94, 13 541-13 552, 1989.

Mikkelsen, I. S., T. S. Jørgensen, M. C. Kelley, M. F. Larsen, E. Pereira, and J. Vickrey, Neutral winds and electric fields in the dusk auroral oval, 1. Measurements, J. Geophys. Res., 86, 1513-1524, 1981.

Millward, G. H., R. J. Moffett, S. Quegan, and T. J. Fuller-Rowell, Effects of an atmospheric gravity wave on the midlatitude ionospheric F layer, J. Geophys. Res., 98, 19 173-19 179, 1993a.

Millward, G. H., S. Quegan, R. J. Moffett, T. J. Fuller-Rowell, and D. Rees, A modelling study of the coupled ionospheric and thermospheric response to an enhanced high-latitude electric field event, Planet. Space Sci., 41, 45-56, 1993 b.

Nagy, A. F., R. J. Cicerone, P. B. Hays, K. D. McWatters, J. W. Meriwether, A. E. Belon, and C. L. Rino, Simultaneous measurement of ion and neutral motions by radar and optical techniques, Radio Sci., 9, 315-321, 1974.

Rees, D., N. Lloyd, P. J. Charleton, M. Carlson, J. Murdin, and I. Häggström, Comparison of plasma flow and thermospheric circulation over northern Scandinavia using EISCAT and a Fabry-Perot interferometer, J. Atmos. Terr. Phys., 46, 545-564, 1984.

Rees, M. H., and R. G. Roble, Excitation of $\mathrm{O}(1 \mathrm{D})$ atoms in aurorae and emission of the [OI] 6300-A line, Can. J. Phys., 64, 1608-1613, 1986.

Rice, D. D., R. D. Hunsucker, L. J. Lanzerotti, G. Crowley, P. J. S. Williams, J. D. Craven, and L. Frank, An observation of atmospheric gravity wave cause and effect during the October 1985 WAGS campaign, Radio Sci., 23, 919-930, 1988.

Richmond, A. D., and S. Matsushita, Thermospheric response to a magnetic substorm, J. Geophys. Res., 80, 2839-2850, 1975.

Sharp, W. E., M. H. Rees, and A. I. Stewart, Coordinated rocket and satellite measurements of an auroral event 2. The rocket observations and analysis, J. Geophys. Res., 84, 1977-1985, 1979.

Sica, R. J., M. H. Rees, R. G. Roble, G. Hernandez, and G. J. Romick, The altitude region sampled by ground-based doppler temperature measurements of the OI $15867 \mathrm{~K}$ emission line in aurorae, Planet. Space Sci., 34, 483-488, 1986.

Strickland, D. J., D. L. Book, T. P. Coffey, and J. A. Fedder, Transport equation techniques for the deposition of auroral electrons, J. Geophys. Res., 81, 2755-2764, 1976.

Strickland, D. J., R. R. Meier, J. H. Hecht, and A. B. Christensen, Deducing composition and incident electron spectra from ground-based auroral optical measurements: theory and model results, J. Geophys. Res., 94, 13 527-13 539, 1989.

Taylor, M. J., and R. Edwards, Observations of short period mesospheric wave patterns: in situ or tropospheric wave generation?, Geophys. Res. Lett., 18, 1337-1340, 1991.

Testud, J., and P. Francois, Important of diffusion processes in the interaction between neutral waves and ionization, J. Atmos. Terr. Phys., 33, 765-774, 1971.

Thuillier, G., C. Lathuillere, M. Herse, C. Senior, W. Kofman, M. L. Duboin, D. Alcayde, F. Barlier, and J. Fontanari, Coordinated EISCAT-MICADO interferometer measurements of neutral winds and temperatures in $E$ - and $F$-regions, J. Atmos. Terr. Phys., 52, 625-636, 1990.

Titheridge, J. E., Periodic disturbances in the ionosphere, J. Geophys. Res., 73, 243-252, 1968.

Williams, P. J. S., T. S. Virdi, R. V. Lewis, M. Lester, A. S. Rodger, I. W. McCrea, and K. S. C. Freeman, Worldwide atmospheric gravity-wave study in the European sector 1985-1990, J. Atmos. Terr. Phys., 55, 683-696, 1993.

Winser, K. J., A. D. Farmer, D. Rees, and A. Aruliah, Ion-neutral dynamics in the high latitude ionosphere: first results from the INDI experiment, J. Atmos. Terr. Phys., 50, 369-377, 1988.

Witasse, O., J. Lilensten, C. Lathuillere, and B. Pibaret, Meridional thermospheric neutral wind at high latitude over a full solar cycle, Ann. Geophysicae, 16, 1400-1409, 1998. 